\title{
Analisis Rasio Kecukupan Modal dan Biaya Operasional Pendapatan Operasional Kinerja Profitabilitas PT. BNI, Tbk Tahun 2015 - 2019
}

\author{
Muysaroh ${ }^{凶}$ \\ Fakultas Ekonomi dan Bisnis Universitas Al-Khairiyah \\ DOI : https://doi.org/10.37531/ecotal.v3i1.117
}

\begin{abstract}
The purpose of this study was to find out how the analysis of the Capital Adequacy Ratio on profitability performance, to find out how the analysis of operating costs of operating income ( BOPO ) on profitability performance, to find out how the analysis of the Capital Adequacy Ratio and the Bopo to profitability performance. The method used in this research is to collect data from financial statements. This study uses data from 2015-2019. The type of data collected is secondary data. The results of this study explain that the Capital Adequacy Ratio in 2015 was 146.1\%, in 2016 it was 62.3\%, in 2017 it was 62.1\%, in 2018 it was $46.4 \%$, in 2019 it was 59. 4\%, the ratio of operating expenses to operating income in 2015 was $46.8 \%$, in 2016 it was $46.5 \%$, in 2017 it was 46.1\%, in 2018 it was 44.7\%, in 2019 it was 45, 5\%., Return On Assets in 2015 was 2.25\%, in 2016 it was $2.37 \%$, in 2017 it was $2.42 \%$, in 2018 it was $2.45 \%$, in 2019 it was $2.29 \%$.
\end{abstract}

Keywords : CAR, BOPO, ROA

\footnotetext{
$\triangle$ Corresponding Author :

E-mail address: mumu8272@gmail.com (Jl. K.H. Ahmad Dahlan No.15, Citangkil, Kec. Citangkil, Banten)

“Received 08 December 2021, Accepted 12 January 2021, Published 24 January 2022"
} 


\section{Pendahuluan}

Semakin ketatnya persaingan antar bank syariah ataupun dengan bank konvensional, bank syariah dituntut buat mempunyai kinerja yang baik, supaya bisa bersaing dalam pasar Perbankan nasional di Indonesia. spesialnya Perbankan. Ini disebabkan bank dalam melakukan aktivitas operasionalnya mau mendapatkan keuntungan yang optimal. Hingga dari itu, bank hendak senantiasa memaksimalkan kinerja keuangan bank tersebut. Bank ialah salah satu lembaga keuangan yang berperan selaku financial intermediary ataupun lembaga perantara antara pihak yang kelebihan dana serta pihak yang kekurangan dana. Semakin kecil rasio ini berarti semakin efisien biaya operasional yang dikeluarkan bank yang bersangkutan sehingga kemungkinan suatu bank ada dalam kondisi bermasalah semakin kecil. Kinerja profitabilitas merupakan gambaran prestasi yang diraih bank dalam melakukan aktivitas operasionalnya, yang pada dasarnya serupa dengan kegiatan ekonomi umunya yaitu untuk memperoleh keuntungan. Profitabilitas merupakan indikator yang paling tepat untuk mengukur kinerja suatu bank., jika kinerja bank menurun maka tingkat kepercayaan masyarakat terhadap bank juga akan berkurang. Dalam penelitian ini profitabilitas akan diproksikan dengan menggunakan Return On Asset sebagai ukuran kinerja bank. Bagi BNI, transformasi menuju layanan digital ini merupakan keharusan guna menghadapi tantangan untuk menjadi bank yang tetap relevan serta menawarkan solusi layanan yang serba cepat, fleksibel, dan mobile kepada nasabahnya.

BNI terus bertransformasi dan mengembangkan serta memperkuat kapabilitas sebagai bank digital. Penerapan digitalisasi pada jaringan distribusi dan proses bisnis telah terbukti mampu menopang pertumbuhan bisnis BNI secara konsisten dari tahun ke tahun melalui perluasan akses pasar maupun efisiensi operasional. Upaya peningkatan kapabilitas teknologi digital diharapkan akan membawa BNI menjadi bank digital yang mampu bersaing di era Industri 4.0 ini.

Bank Negara Indonesia sebagai bank BUMN pertama yang didirikan dan dimiliki pemerintah diharapkan mampu menjaga dan mengawasi kredit yang diberikan kepada masyarakat agar dapat meminimalisir terjadinya risiko kredit dan risiko likuiditas. Kondisi Rasio Kecukupan Modal dan rasio Biaya Operasional Pendapatan Operasional ( BOPO ) pada Bank Negara Indonesia dapat dilihat pada Tabel 1 berikut. 
Tabel 1. Tabel rasio CAR dan BOPO tahun 2015-2019

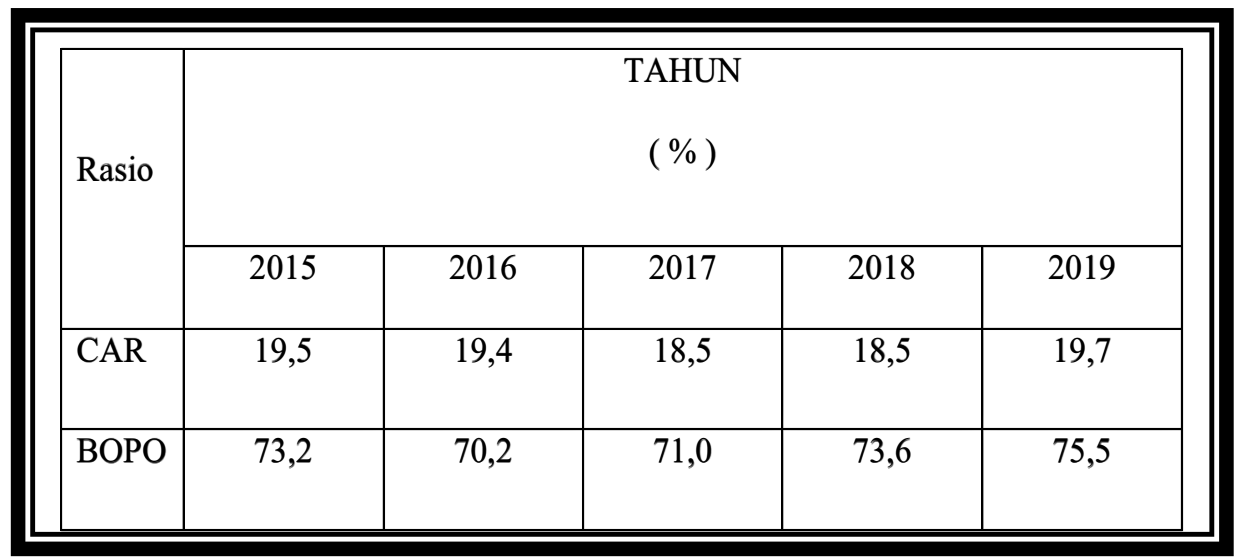

CAR pada sampel diatas menunjukkan penurunan yang terjadi pada tahun 2016. Pada tahun 2016 mengalami penurunan sebesar 0,1\% dari tahun 2015. Pada tahun 2017 mengalami penurunan dengan derastis sebesar 0,9\% dari tahun 2016. pada tahun 2019 mengalami kenaikan sebesar 1,2\% dari tahun 2018. BOPO pada sampel diatas menunjukkan penurunan yang terjadi pada tahun 2016. Pada tahun 2016 mengalami penurunan sebesar 3\% dari tahun 2015. Pada tahun 2017 mengalami kenaikan sebesar 0,8\% dari tahun 2016. Pada tahun 2018 BOPO mengalami kenaikan yang cukup signifikan yaitu sebesar 2,6\% dari tahun 2017, dan pada tahun 2019 mengalami kenaikan sebesar 2,1\% dari tahun 2018

\section{Kajian Literatur}

\section{Rasio Kecukupan Modal}

Capital adequacy ratio (CAR) merupakan rasio kecukupan modal yang dapat menunjukkan kemampuan bank dalam menyediakan dana serta menampung kemungkinan resiko kerugian yang diakibatkan dalam operasional bank. hubungan antara rasio kecukupan modal dengan perbankan adalah sangat penting mengingat modal bank berfungsi sebagai pelindung seandainya nilai aset bank menurun atau kewajibannya meningkat. (Triana Anugrah dan Chicilia Nova Yatna $2019 ; 135)$

Dengan kata lain, Capital Adequacy Ratio adalah rasio kinerja perusahaan untuk mengukur kecukupan modal yang dimiliki perusahaan untuk menunjang aktiva yang mengandung atau menghasilkan resiko. Permodalan (Capital Adequacy ratio) menunjukkan kemampuan bank dalam mempertahankan modal yang mencukupi dan kemampuan manajemen bank dalam mengidentifikasi, mengawasi dan mengontrol resiko-resiko yang timbul yang dapat berpengaruh terhadap besarnya modal bank (Sufa, 2008). 


\section{Biaya operasional pendapatan operasional}

Rasio biaya operasional pendapatan operasional adalah Rasio yang sering disebut rasio efisiensi ini digunakan untuk mengukur kemampuan manajemen bank dalam mengendalikan biaya operasional terhadap pendapatan operasional. Semakin kecil rasio ini berarti semakin efisien biaya operasional yang dikeluarkan bank yang bersangkutan sehingga kemungkinan kondisi suatu bank bermasalah semakin kecil. Biaya operasional dihitung berdasarkan penjumlahan dari total beban bunga dan total beban operasional lainnya. Pendapatan operasional adalah penjumlahan dari total pendapatan bunga dan total pendapatan operasional lainnya. (Nurul Rahmi \& Ratna Anggraini, 2013;117).

\section{Profitabilitas}

Profitabilitas Adalah rasio yang mengukur tentang kemampuan perusahaan menghasilkan keuntungan pada tingkat penjualan, aset, maupun modal saham tertentu. Indikator yang digunakan untuk mengukur tingkat profitabilitas yaitu Return On Asset (ROA) dan return on equity (ROE) pada dasarnya keduanya dapat digunakan, akan tetapi dalam penelitian ini profitabilitas diproksikan dengan Return On Asset (ROA) sebagai ukuran kinerja bank, sedangkan return on equity (ROE) hanya mengukur return yang diperoleh dari investasi pemilik perusahaan.( Dahlan siamat,2007;112) Profitabilitas (profitability) adalah kemampuan suatu bank dalam memperoleh laba. Dalam penelitian ini indikator yang digunakan dalam rasio profitabilitas ini adalah ROA (Return On Asset).

\section{Return on asset}

Menurut lampiran Surat Edaran Bank Indonesia (SEBI) Nomor 15/43/DPNP tanggal 21 Oktober 2013 Return On Assets (ROA) adalah perbandingan antara laba sebelum pajak dalam 12 (dua belas) bulan terakhir dibandingkan dengan rata-rata Volume Usaha dalam periode yang sama sesuai dengan ketentuan Bank Indonesia. Return On Assets atau ROA adalah rasio yang menunjukkan perbandingan antara laba (sebelum pajak) dengan total asset bank, rasio ini menunjukkan tingkat efisiensi pengelolaan asset yang dilakukan oleh bank yang bersangkutan (Pandia, 2012:71). Kinerja profitabilitas merupakan gambaran prestasi yang diraih bank dalam melakukan aktivitas operasionalnya, yang pada dasarnya serupa dengan kegiatan ekonomi umunya yaitu untuk memperoleh keuntungan.

\section{Metode Penelitian}

Jenis penelitian yang digunakan peneliti yaitu penelitian deskriptif kualitatif. Metode kualitatif digunakan untuk mendapatkan data yang mendalam, suatu data yang mengandung makna. Sumber data yang digunakan untuk penelitian ini adalah data primer dan data sekunder. Adapun teknik pengumpulan data yang penulis gunakan antara lain: Observasi, tinjauan pustaka, dan wawancara. Teknik analisis data yang digunakan dalam penelitian ini adalah teknik analisis kuantitatif, yaitu suatu analisis yang dilakukan melalui pengukuran berupa angka-angka dengan menggunakan metode kuantitatif. 


\section{Muysaroh ${ }^{凶}$}

Analisis Rasio Kecukupan Modal dan Biaya Operasional......

DOI : https://doi.org/10.37531/ecotal.v3i1.117

\section{Hasil Penelitian dan Pembahasan}

Tabel 6. Tabel data penelitian (dalam miliar persen)

\begin{tabular}{|c|c|c|c|}
\hline No & Komponen laporan keuangan & Tahun & Jumlah \\
\hline \multirow{5}{*}{1} & \multirow{5}{*}{ MODAL } & 2015 & Rp.78.438 \\
\hline & & 2016 & Rp.89.254 \\
\hline & & 2017 & Rp. 100.903 \\
\hline & & 2018 & Rp.110.374 \\
\hline & & 2019 & Rp.125.004 \\
\hline \multirow{5}{*}{2} & \multirow{5}{*}{ ATMR } & 2015 & $19.5 \%$ \\
\hline & & 2016 & $19.4 \%$ \\
\hline & & 2017 & $18.5 \%$ \\
\hline & & 2018 & $18.5 \%$ \\
\hline & & 2019 & $19.7 \%$ \\
\hline \multirow{5}{*}{3} & \multirow{5}{*}{ Biaya operasional } & 2015 & Rp.16.510 \\
\hline & & 2016 & Rp.19.217 \\
\hline & & 2017 & Rp.20.863 \\
\hline & & 2018 & Rp.21.783 \\
\hline & & 2019 & Rp.23.687 \\
\hline
\end{tabular}

\begin{tabular}{|c|c|c|c|}
\hline \multirow{5}{*}{4} & \multirow{5}{*}{ Pendapatan operasional } & 2015 & Rp.35.258 \\
\hline & & 2016 & Rp.41.299 \\
\hline & & 2017 & Rp. 45.212 \\
\hline & & 2018 & Rp.48.771 \\
\hline & & 2019 & Rp.52.012 \\
\hline \multirow{5}{*}{5} & \multirow{5}{*}{ Laba sebelum pajak } & 2015 & Rp.11.466 \\
\hline & & 2016 & Rp.14.303 \\
\hline & & 2017 & Rp.17.165 \\
\hline & & 2018 & Rp.19.821 \\
\hline & & 2019 & Rp.19.370 \\
\hline \multirow{5}{*}{6} & \multirow{5}{*}{ Total asset } & 2015 & Rp. 508.595 \\
\hline & & 2016 & Rp. 603.032 \\
\hline & & 2017 & Rp.709.330 \\
\hline & & 2018 & Rp.808.572 \\
\hline & & 2019 & Rp.845.605 \\
\hline
\end{tabular}

Sumber: Laporan Keuangan PT.Bank Negara Indonesia Tbk www.BNI.co.id (data sudah diolah)

Tabel 7. Perhitungan rasio kecukupan modal PT.Bank Negara Indonesia Tbk.

\begin{tabular}{|c|c|c|c|c|}
\hline \multirow{2}{*}{ Tahun } & $\begin{array}{c}\text { Modal } \\
(\%)\end{array}$ & $\begin{array}{c}\text { ATMR } \\
(\%)\end{array}$ & $\begin{array}{c}\text { Jumlah CAR } \\
(\%)\end{array}$ & Peneliian \\
\hline 2015 & 28.5 & 19.5 & 146,1 & Sangat sehat \\
\hline 2016 & 12.1 & 19.4 & 62,3 & Sangat sehat \\
\hline 2017 & 11.5 & 18.5 & 62,1 & Sangat sehat \\
\hline 2018 & 8.6 & 18.5 & 46,4 & Sangat sehat \\
\hline 2019 & 11.7 & 19.7 & 59,4 & Sangat sehat \\
\hline
\end{tabular}

Sumber: Laporan Keuangan PT.Bank Negara Indonesia Tbk www.BNI.co.id (data sudah diolah) 
Dari tabel diatas, Pada tahun 2015 modal 28,5\% dengan 19.5 menghasilkan CAR 146,1 \% . hasil tersebut jika dikaitkan dengan pedoman penelitian kriteria penilaian peringkat analisis CAR termasuk sangat baik. Pada tahun 2016 modal yang terjadi sebesar 12,1\% sedangkan kan ATMR 19,4\% menghasilkan CAR 62,3\%. Hasil tersebut jika dikaitkan dalam penelitian kriteria penilaian peringkat analisis CAR. termasuk kriteria sangat baik. Pada tahun 2017 modal yang terjadi sebesar 11,5\% sedangkan kan ATMR 18,5\% menghasilkan CAR 62,1\%. Hasil tersebut jika dikaitkan dalam penelitian kriteria penilaian peringkat analisis CAR. termasuk kriteria sangat baik. Pada tahun 2018 modal yang terjadi sebesar 8,6\% sedangkan kan ATMR 18,5\% menghasilkan CAR 1,36\%. Hasil tersebut jika dikaitkan dalam penelitian kriteria penilaian peringkat analisis CAR. termasuk kriteria sangat baik. Pada tahun 2019 modal yang terjadi sebesar 11,7\% sedangkan kan ATMR 19,7\% menghasilkan CAR 59,4\%.. termasuk kriteria sangat baik.

$$
\mathrm{CAR}=\frac{M O D A L}{A T M R} X 100 \%
$$

Tabel 8. Perhitungan Biaya Operasional Pendapatan Operasional PT.Bank Negara Indonesia Tbk. (dinyatakan dalam persen)

\begin{tabular}{|c|c|c|c|c|}
\hline Tahun & $\begin{array}{c}\text { Biaya } \\
\text { operasional (Rp) }\end{array}$ & $\begin{array}{c}\text { Pendapatan } \\
\text { operasional (Rp) }\end{array}$ & $\begin{array}{c}\text { Jumlah } \\
\text { BOPO (\%) }\end{array}$ & penelitian \\
\hline 2015 & 16.510 & 35,258 & 46,8 & Sehat \\
\hline 2016 & 19.217 & 41,299 & 46,5 & Sehat \\
\hline 2017 & 20.863 & 45,212 & 46,1 & Sehat \\
\hline 2018 & 21.783 & 48,771 & 44,7 & Sehat \\
\hline 2019 & 23.687 & 52,012 & 45,5 & Sehat \\
\hline
\end{tabular}

Sumber: Laporan Keuangan PT.Bank Negara Indonesia Tbk www.BNI.co.id (data sudah diolah)

Dari table diatas, Pada tahun 2015 biaya operasional Rp.16.510 dengan pendapatan operasional Rp.35,258 menghasilkan BOPO 46,8\%. hasil tersebut jika dikaitkan dengan pedoman penelitian kriteria penilaian tingkat kesehatan BOPO tahun 2007 termasuk dalam kriteria sehat. 
Pada tahun 2016 biaya operasional Rp.19.217 dengan pendapatan operasional Rp.41,299 menghasilkan BOPO 46,5\%. jika dikaitkan dengan pedoman penelitian kriteria penilaian tingkat kesehatan BOPO tahun 2007 termasuk dalam kriteria sehat.

Pada tahun 2017 biaya operasional Rp.20.863 dengan pendapatan operasional Rp.45,212 menghasilkan BOPO 46,1\%. jika dikaitkan dengan pedoman penelitian kriteria penilaian tingkat kesehatan BOPO tahun 2007 termasuk dalam kriteria sehat.

Pada tahun 2018 biaya operasional Rp.21.783 dengan pendapatan operasional Rp.48,771 menghasilkan BOPO 44,6 \%. jika dikaitkan dengan pedoman penelitian kriteria penilaian tingkat kesehatan BOPO tahun 2007 termasuk dalam kriteria sehat.

Pada tahun 2019 biaya operasional Rp.23.687 dengan pendapatan operasional Rp.52,012 menghasilkan BOPO 45,5\%. jika dikaitkan dengan pedoman penelitian kriteria penilaian tingkat kesehatan BOPO tahun 2007 termasuk dalam kriteria sehat.

$\mathrm{BOPO}=\frac{\text { biaya oprasional }}{\text { pendapatan oprasional }} \times 100 \%$

Tabel 9. Perhitungan Return On Asset PT.Bank Negara Indonesia Tbk. (dinyatakan dalam persen)

\begin{tabular}{|c|c|c|c|c||}
\hline Tahun & $\begin{array}{c}\text { Laba sebelum pajak } \\
(\mathrm{Rp})\end{array}$ & $\begin{array}{c}\text { Total asset } \\
(\mathrm{Rp})\end{array}$ & $\begin{array}{c}\text { Jumlah ROA } \\
(\%)\end{array}$ & Hasil \\
& 11.466 & 508.595 & 2.25 & Sehelitian \\
\hline 2015 & 14.303 & 603.032 & 2.37 & Sehat \\
\hline 2016 & 17.165 & 709.330 & 2.42 & Sehat \\
\hline 2017 & 19.821 & 808.572 & 2.45 & Sehat \\
\hline 2018 & 19.370 & 845.605 & 2.29 & Sehat \\
\hline 2019 & \multicolumn{3}{|l}{} \\
\hline
\end{tabular}

Sumber: Laporan Keuangan PT.Bank Negara Indonesia Tbk www.BNI.co.id (data sudah diolah).

Dari table diatas, Pada tahun 2015 biaya operasional Rp. 16.510 dengan pendapatan operasional Rp.35,258 menghasilkan BOPO 46,8\%. hasil tersebut jika dikaitkan dengan pedoman penelitian kriteria penilaian tingkat kesehatan BOPO tahun 2007 termasuk dalam kriteria sehat.

Pada tahun 2016 biaya operasional Rp. 19.217 dengan pendapatan operasional 
Rp.41,299 menghasilkan BOPO 46,5\%. jika dikaitkan dengan pedoman penelitian kriteria penilaian tingkat kesehatan BOPO tahun 2007 termasuk dalam kriteria sehat.

Pada tahun 2017 biaya operasional Rp. 20.863 dengan pendapatan operasional Rp.45,212 menghasilkan BOPO 46,1\%. jika dikaitkan dengan pedoman penelitian kriteria penilaian tingkat kesehatan BOPO tahun 2007 termasuk dalam kriteria sehat.

Pada tahun 2018 biaya operasional Rp. 21.783 dengan pendapatan operasional Rp.48,771 menghasilkan BOPO 44,6 \%. jika dikaitkan dengan pedoman penelitian kriteria penilaian tingkat kesehatan BOPO tahun 2007 termasuk dalam kriteria sehat.

Pada tahun 2019 biaya operasional Rp. 23.687 dengan pendapatan operasional Rp.52,012 menghasilkan BOPO 45,5\%. jika dikaitkan dengan pedoman penelitian kriteria penilaian tingkat kesehatan BOPO tahun 2007 termasuk dalam kriteria sehat.

Return On Asset $=\frac{\text { laba sebelum pajak }}{\text { total asset }} \times 100 \%$

\section{Kesimpulan}

Kinerja profitabilitas merupakan gambaran prestasi yang diraih bank dalam melakukan aktivitas operasionalnya, yang pada dasarnya serupa dengan kegiatan ekonomi umunya yaitu untuk memperoleh keuntungan. Profitabilitas merupakan indikator yang paling tepat untuk mengukur kinerja suatu bank. Dengan diketahuinya kinerja bank yang baik maka tingkat kepercayaan masyarakat terhadap bank akan meningkat, dan sebaliknya, jika kinerja bank menurun maka tingkat kepercayaan masyarakat terhadap bank juga akan berkurang.

\section{References :}

Anugrah Triana dan Yatna Nova Chicilia,2019, Pengaruh Non Performing Loan, Loan To Deposit Ratio, Net Interest Margin, Biaya Operasional Pendapatan Operasional Dan Capital adequacy ratio Terhadap Profitabilitas Bank Umum Konvensional Buku 4 Periode 2012-2016

Hendrawati Oktober,2018 Pengaruh Capital adequacy ratio (Car), Quick Ratio, Rasio Biaya Operasional Terhadap Pendapatan Operasional ( BOPO ) Terhadap Return On Equity (Roe) Pada Bank Konvensional Di Indonesia Periode 2010 - 2014

Juliana Sisca Dan Mulazid Ade Sofyan,2017 Analisa Pengaruhbopo, Kecukupan Modal, Pembiayaan Bermasalah, Bagi Hasil Dan Profitabilitas Terhadap Simpanan Mudharabah Pada Bank Umum Syariah Periode 2011-2015,

Juliana Sisca dan Mulazid Sofyan Ade Juni 2017 Analisa PengaruhBOPO, Kecukupan Modal, Pembiayaan Bermasalah, Bagi Hasil Dan Profitabilitas Terhadap Simpanan Mudharabah Pada Bank Umum Syariah Periode 2011-2015 
Nurdin Ismail dan Hartati, Sri metodologi Penelitian Sosial, (surabaya: Media Sahabat Cendikia 2019)

Rahmi Nurul \& Anggraini Ratna Pengaruh Car, Bopo, Npf, Dan Csr Disclosure Terhadap Profitabilitas Perbankan Syariah Jurnal Ilmiah Wahana Akuntansi Tahun 2013

Sanusi Anwar, Metodologi Penelitian Bisnis, Salemba Empat, Jakarta, 2011, siamat Dahlan, manajemen lembaga keuangan, ( jakarta:lembaga penerbit FEUI,2007)

sugiyono 12 februari 2011 metode penelitian kuantitatif kualitatif dan D\&R penerbit alfabeta, bandung cetakan ke halaman

Sugiyono 2017.statistika untuk penelitian cetakan ke-28 Alfabeta, Bandung,

Sugiyono Metode Penelitian Kuantitatif, Kualitatif, Dan R\&D, Cetakan Ke-12, Alfabeta, Bandung, 2011

Sugiyono, Metode Penelitian Bisnis, Cetakan 16, Alfabeta, Bandung 2012, Hal 8

Susanto Herry, \& umam khaerul manajemen pemasaran bank syariah cet. 1 bandung: pustaka setia2013,

Zulfachri Budi November 2017 Pengaruh Antara Rasio Kecukupan Modal (CAR), Loan To Deposit Ratio (LDR), dan Rasio Biaya Operasional Pendapatan Operasional ( BOPO) terhadap Kinerja Profitabilitas Industri Perbankan Jurnal Manajemen Dan Keuangan 